\title{
Modelling and Analysis of an Automotive Bumper Used for a Low Passenger Vehicle
}

\author{
Alen John ${ }^{\# 1}$, Nidhi M.B ${ }^{* 2}$ \\ ${ }^{\#}$ P.G Scholar, Department of Mechanical Engineering, Mar Baselios College of Engineering \& Technology, Trivandrum, India. \\ *Assistant Professor, Department of Mechanical Engineering, Mar Baselios College of Engineering \& Technology, Trivandrum, \\ India.
}

\begin{abstract}
Automotive design with economy, safety and aesthetics have been a great challenge to design engineers. Augmenting to these factors today environment impact is an upcoming research area. The safety of the passengers during vehicle crashes can be ensured to a certain limit by using good bumpers. At the same time these automotive parts should not be massive in terms of weight contributing to the increase in total the weight of the vehicle. In this work, a bumper used for low passenger vehicle, Ambassador car is modelled by using the software CATIA V5R18. Then this model is imported into FEM package of ABAQUS 6.10 impact as well as static analysis. Again modal analysis and analysis under dynamic loading done for the same model using ANSYS Workbench 11.0. The materials used for these analyses are Aluminum B390 alloy, Chromium coated mild steel and carbon composite. During static analysis, Carbon composite shows the lowest deformation and maximum von mises stress value. After the impact analysis, the composite shows the highest stress value, lowest deformation and the lowest strain value on compared with above materials. The analysis under the dynamic loading shows this carbon composite has the maximum stress value and it having the highest strength to weight ratio and producing low deformation. From all these analysis, it can concluded that carbon composite is the best material which can use as the bumper material among all the other materials used here.
\end{abstract}

Keywords- bumper materials, impact analysis, low passenger vehicle, Composite, alloys.

\section{INTRODUCTION}

The development in technology demands engineering design field to be competitive and creative to meet the challenging competition. Nowadays, careful attention in meeting precision, ecofriendly products and modularity in designing are gaining importance. The demand for new and customised personal vehicles are increasing at an exponential rate with the increase in buying power of customers. Transportation is identified as the major sector contributor to the accidents and the $\mathrm{CO} 2$ emissions [1]. The greatest challenges faced by the automotive industry has been to provide safer vehicles with high fuel efficiency at competitive cost. Automotive design with economy, safety and aesthetics have been a great challenge to design engineers. Current automotive vehicle structures have one fundamental handicap, a short crumple zone for crash energy absorption. Augmenting to these factors today environment impact is an upcoming research area. The crashes of vehicles are common in the present scenario. The crashes Side impact crashes accounted for 25 percent of all injury crashes and 40 percent of serious injury crashes where an occupant was either hospitalized or killed [3]. Vehicle side impact occupant protection research has concentrated mostly on the occupants seated beside the struck side of the vehicle. These occupants are defined as near-side occupants. All regulatory side impact test standards focus exclusively on this scenario and rely on an assessment provided by one test intended to represent one point in the spectrum of real world near-side impact crashes [4].The safety of the passengers during vehicle crashes can be ensured to a certain limit by using good bumpers. At the same time these automotive parts should not be massive in terms of weight contributing to the increase in total the weight of the vehicle. The most commonly used automotive vehicle are low passenger vehicles like cars. As compared with the other vehicles, the bumpers provides safety as well as aesthetic look in these low passenger vehicle.

The automobile bumper weight can be reduced by the use of composite and high- strength metallic sheet of a thin material. When the automobile is hit from the front or behind, the bumper beam collapses. The impact force is transmitted to the left and right front frames along the bumper beam and bumper stays [7]. The impact energy produced during the crash is absorbed by plastic deformation on the bumper beam and bumper stays which are the important parts of the bumper [8]. So while manufacturing a bumper, the following criteria are considered 1) fit to both the front and rear of vehicles, 2) replaceable without cutting or welding 3 ) incorporate a beam height exceeding $100 \mathrm{~mm}$, positioned to fully engage with the front and rear bumper barriers 4) torsion-resistant to carry eccentric loads without twisting, absorb energy and restrict damage to the bumper system only 5) can attach to the body via energy absorbing structures that are inexpensive to repair or replace 6) be stable during impacts to prevent under ride and override[6]. Automotive manufacturers around the world are racing to revolutionize cars and trucks to reduce their carbon footprint while copying to meet consumer and industry needs. The aluminium content use in automotive vehicle will nearly double by 2025[9]. Carbon fibre composites has the ability to perform extremely well in the case of a crash. They are being used in the manufacturing of different dedicated energy absorbing components in the automobile world and in the constructions of aerospace engineering. The rising trend ensures high strength to weight ratio in the automobile and aerospace engineering. In the metallic structures energy absorption is achieved through the plastic deformation which varies accordingly with material properties [10]. 
For identifying the best material, various analysis like static analysis, impact or crash analysis, dynamic and modal analysis are required. Finite Element Analysis being the practical application of the finite element method (FEM), is used by engineers and scientist to mathematically model and numerically solve very complex structural, fluid, and multi physics problems scenario. Computational tools are used when experimental study becomes complex and expensive. Computational tools of FEA helps in saving cost and time in studying economic design and enable alternative study on various materials and its properties under varying loads [11]. So Finite Element Analysis is considered for analysis in this work.

The objective of the work is to identify the best material for bumper which will ensure passenger safety, with high strength to weight ratio through the static, impact analysis and having dynamic stability using different engineering materials like Aluminium B390 alloy, Chromium coated mild steel and carbon composite. This document is a template. An electronic copy can be downloaded from the conference website. For questions on paper guidelines, please contact the conference publications committee as indicated on the conference website. Information about final paper submission is available from the conference website.

\section{SOLID MODELLING}

Solid modelling is a set of principles for mathematical and computer modelling of three-dimensional solids and is distinguished from related areas of geometric modelling and computer graphics by its emphasis on physical fidelity [6].

At first the two dimensional drawing of the bumper is fixed. From main menu we go to 'mechanical design' and then to 'part design. Then select the required plane. Then draw circle by considering the dimensions by using the 'sketch' option. Then the required lines are drawn. To exit from workbench, use the 'exit workbench' command. Use the 'pad' option for making these two dimensional drawing into the required one with dimensions. . In between them usage of necessary steps like slot, pad and mirror options are also necessary for obtaining the desired model from the 'mechanical design' menu option. The various views of the bumper are shown here from figures 1 to 2 .

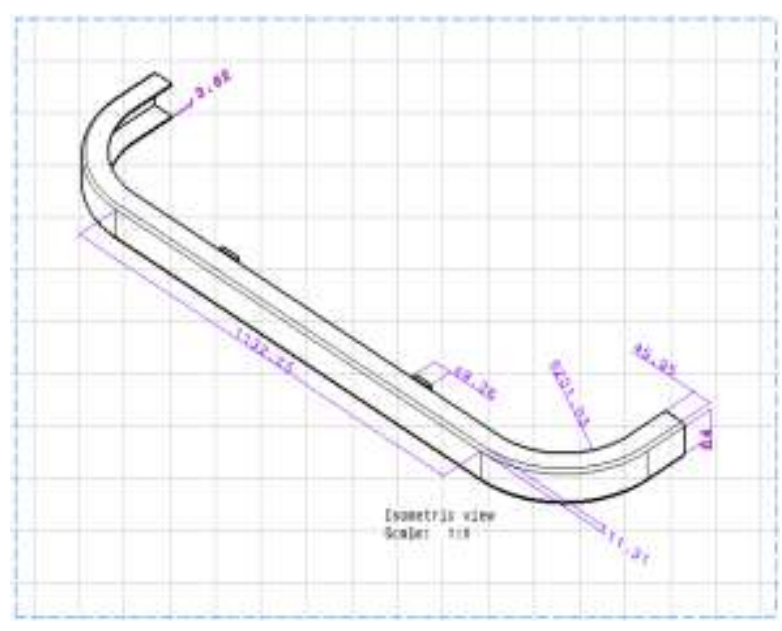

Fig. 1. Isometric view of the Bumper

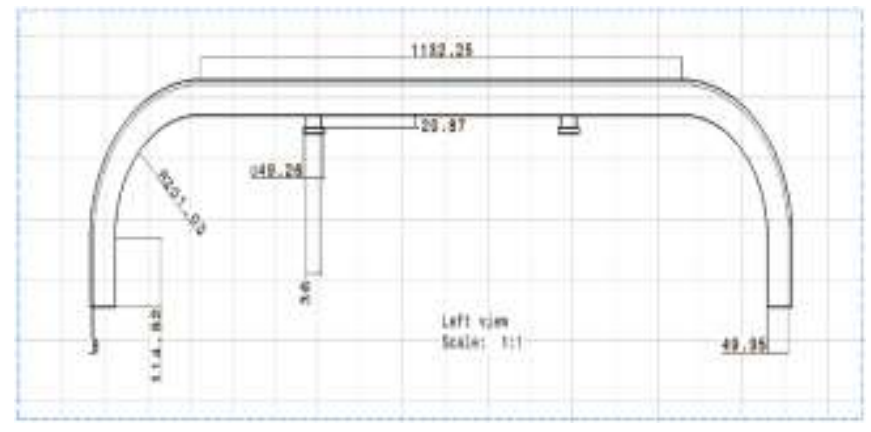

Fig. 2.Left view of the Bumper

\section{MATERIALS USED}

The different materials used to analyses this bumper model are aluminium B390 alloy, HMC Carbon fiber and chromium coated Mild steel. The different properties which are used in this analysis are mentioned in table 1 . Since the Carbon fibre composite having some difference in its material property with other, so it is shown in table 2.

TABLE I.

DETAILS OF MATERIAL PROPERTIES

\begin{tabular}{|c|c|c|c|c|c|}
\hline Material & $\begin{array}{c}\text { Density } \\
\left(\mathbf{k g} / \mathbf{m}^{\mathbf{3}}\right)\end{array}$ & $\begin{array}{c}\text { Young } \\
\text { Modulus } \\
\text { (GPa) }\end{array}$ & $\begin{array}{c}\text { Poisson } \\
\text { ratio }\end{array}$ & $\begin{array}{c}\text { Yield } \\
\text { stress } \\
\text { (MPa) }\end{array}$ & $\begin{array}{c}\text { Fracture } \\
\text { strain }\end{array}$ \\
\hline $\begin{array}{c}\text { Mild steel } \\
\text { (chromium } \\
\text { coated) }\end{array}$ & 7800 & 210 & 0.3 & 300 & 16.6 \\
\hline $\begin{array}{c}\text { Aluminium } \\
\text { B390 alloy }\end{array}$ & 2710 & 81.3 & 0.33 & 250 & 28.7 \\
\hline
\end{tabular}

TABLE II.

MATERIAL PROPERTY FOR THE COMPOSITE

\begin{tabular}{|c|c|c|c|c|c|}
\hline Material & $\begin{array}{c}\text { Density } \\
\left(\mathbf{k g} / \mathbf{m}^{3}\right)\end{array}$ & $\begin{array}{c}\text { Young } \\
\text { Modulus } \\
(\mathbf{G P a})\end{array}$ & $\begin{array}{c}\text { Poisson } \\
\text { ratio }\end{array}$ & $\begin{array}{c}\text { Fracture } \\
\text { Stress } \\
\text { (MPa) }\end{array}$ & $\begin{array}{c}\text { Shear } \\
\text { retention } \\
\text { factor }\end{array}$ \\
\hline $\begin{array}{c}\text { Carbon } \\
\text { fiber } \\
\text { composite }\end{array}$ & 1600 & 85 & 0.15 & 150 & 1 \\
\hline
\end{tabular}

\section{FinITE ELEMENT ANALYSIS}

The CATIA model obtained is imported into ABAQUS for static and impact analysis. After this, the same model is imported into ANSYS Workbench for analyzing the dynamic stability with modal analysis and harmonic response analysis.

\section{A. Procedure for static analysis.}

The values of different properties like mass density, Young's modulus, Poisson's ratio and thermal conductivity are entered into software. Another important step is the meshing, which is completed by giving the seeds and global size as 50 to get finer by selecting the part mesh using 
C3D10M element. Then the next step in the analysis is insertion of step into the software. This analysis is based on static (general) type analysis. After this, one has to apply the boundary condition and the load. While applying the boundary condition, the selection of area at which motions are arresting is also important. The calculation of the load is given as follows after these figures.

\section{1) Input data:}

$\begin{array}{ll}\text { Mass of the car(Ambassador) } & =1554 \mathrm{~kg} \\ \text { Average mass of } 5 \text { persons } & =350 \mathrm{~kg} \\ \text { Total mass } & =1554+350 \\ & =1894 \mathrm{~kg} \\ \text { Speed of the car } & =36 \mathrm{~km} / \mathrm{hour} \\ & =10 \mathrm{~m} / \mathrm{s} .\end{array}$

Assume this car is hitting at another identical one and it will stop in 0.1 seconds.

Deceleration of the car

$$
\begin{aligned}
& \frac{u-v}{t} \\
= & (10-0) / 0.1 \\
= & 100 \mathrm{~m} / \mathrm{s}^{2}
\end{aligned}
$$

$\mathrm{v}=$ final velocity of car in $\mathrm{m} / \mathrm{s}, \mathrm{u}=$ initial velocity of car in $\mathrm{m} / \mathrm{s}, \mathrm{t}=$ time after which vehicle stopped in seconds.

Force acted during collision $\quad=m^{* a}$

$$
=1894 * 100
$$$$
=189.4 \mathrm{KN}
$$

$\mathrm{m}=$ mass of car in $\mathrm{kg}, \mathrm{a}=$ acceleration of car in $\mathrm{m} / \mathrm{s}^{2}$

For the easiness of calculation this force is converted into a pressure which is acted on the front surface of the modelled bumper.

$$
\begin{aligned}
\text { Area of the front face of bumper } & =1 * \mathrm{~b} \\
& =1132.25^{*} 64 \mathrm{~mm}^{2} \\
& =0.072464 \mathrm{~m}^{2}
\end{aligned}
$$

$\mathrm{l}=$ length of front face in $\mathrm{mm}, \mathrm{b}=$ breadth of front face in $\mathrm{mm}$

Pressure acted on the bumper

$$
\begin{aligned}
& =\frac{F}{A} \\
& =\frac{189400}{0.072464} \\
& =2613711.64 \mathrm{~N} / \mathrm{m}^{2} \\
& =2.61 * 10^{6} \mathrm{~N} / \mathrm{m}^{2}
\end{aligned}
$$

$\mathrm{F}=$ Force acted during collision in Newtons, $\mathrm{A}=$ Area of the front face of bumper in $\mathrm{m}^{2}$.

The figure 3 shows the faces where boundary condition and the load is applied, it is clear that back face of this model is kept fixed and a pressure of $2.61 \mathrm{MPa}$ is given to the front face of this model.

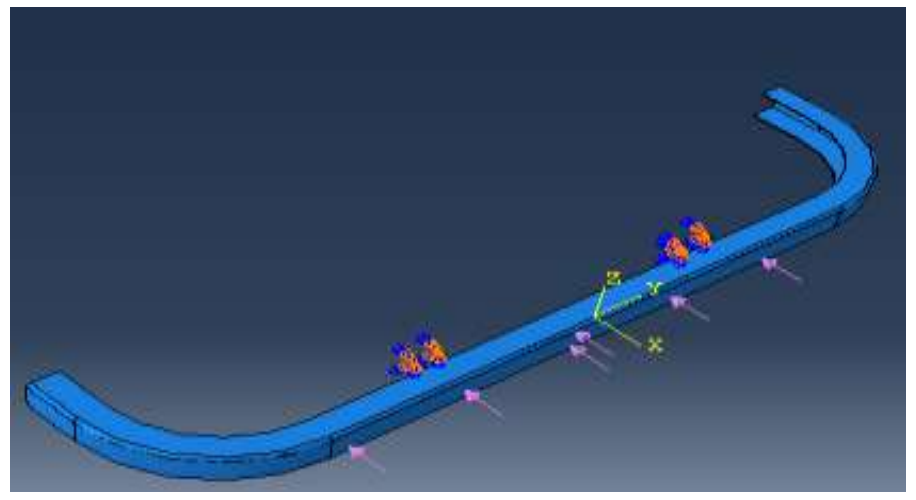

Fig. 3: Boundary condition and load applied on the model.

\section{B. Procedure for impact analysis.}

Dynamic-explicit type of analysis is used for completion of impact analysis in ABAQUS. Then the creation of a datum point at the center of the plate is necessary. For meshing the seeding is important, in the seeding the entire geometry is divided into small elements having size 35. Type of element used is C3D10M (10-node modified quadratic tetrahedron). The meshing of the entire geometry results in 5873 nodes and 2762 elements. Meshing is only needed to the bumper.

\section{1). Application of Load and Boundary condition}

For an analysis, one of the important step is the application of load and boundary condition. In these type of analysis, the important parameters are the velocity and the arresting on the motion at which surface this body is hitting. In this case, a velocity of $10 \mathrm{~m} / \mathrm{sec}$ which is equivalent to 36 $\mathrm{km} /$ hour is applied for the bumper in $\mathrm{x}$ direction which can be clearly identified from Figure 4.

TABLE III.

PRESSURE ACTED DOWNWARDS DUE TO MATERIAL SELF-WEIGHT.

\begin{tabular}{|c|c|c|c|c|}
\hline Material & $\begin{array}{c}\text { Density } \\
\left(\mathbf{k g} / \mathbf{m}^{\mathbf{3}}\right)\end{array}$ & $\begin{array}{c}\text { Mass } \\
(\mathbf{k g})\end{array}$ & $\begin{array}{c}\text { Force } \\
(\mathbf{N})\end{array}$ & $\begin{array}{c}\text { Pressure } \\
(\mathbf{P a})\end{array}$ \\
\hline $\begin{array}{c}\text { Mild steel } \\
\text { (chromium } \\
\text { coated) }\end{array}$ & 7800 & 12.944 & 126.98 & 1220.96 \\
\hline $\begin{array}{c}\text { Aluminum B390 } \\
\text { alloy }\end{array}$ & 2710 & 4.4974 & 44.119 & 424.221 \\
\hline $\begin{array}{c}\text { Carbon fiber } \\
\text { composite }\end{array}$ & 1600 & 2.6533 & 26.048 & 250.46 \\
\hline
\end{tabular}

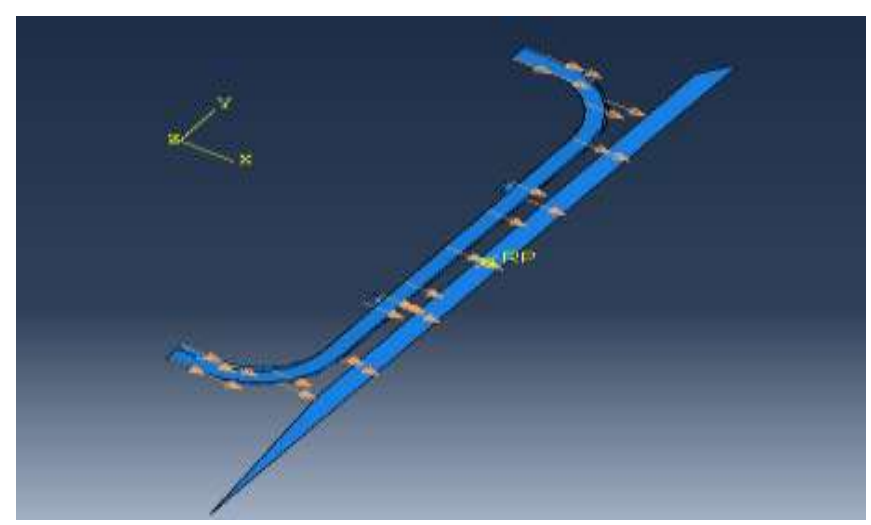

Fig. 4. Velocity of $10 \mathrm{~m} / \mathrm{sec}$ in $\mathrm{x}$ direction. 
The application of the boundary condition in an impact analysis is that surface at which the body is crashed should have been fixed before the analysis. Here the plate is fixed. A point had been made in the plate at the center of the plate and make that point into a reference point.

\section{Procedure for Modal Analysis}

In the modal analysis, the number of mode shapes which we have to extract should be specified. This analysis was done by using ANSYS Workbench 11.0. The limit of the frequency range can be given as an input if required. In this case, only first 10 modes are found out and frequency limit given as 0 to $1000 \mathrm{~Hz}$ during the analysis. Then the entire model is meshed into small elements by using fine mesh. During meshing the entire model is divided into 10752 elements having 4120 nodes by using solid185 element.

\section{Procedure of Dynamic Analysis in ANSYS}

After completing this step the harmonic response analysis should be carried out to find out the total deformation, von mises stress and strain components at various frequencies. In this analysis all loads as well as the structure's response vary sinusoidally at the same frequency. A typical harmonic analysis will calculate the response of the structure to cyclic loads over a frequency range and obtain a graph of some response quantity (usually displacements) versus frequency. "Peak" responses are then identified from graphs of response vs. frequency and stresses are then reviewed at those peak frequencies.

Separate meshing and material selections are not necessary, since this harmonic analysis are doing as a continuation of the modal analysis which is completed in ANSYS Workbench 11.0. In the analysis setting option of the software, we have to select the range minimum and maximum of frequency, mode frequency range, number of modes, mode range minimum and maximum, constant damping ratio as 0.01 etc. After completing this boundary condition and the load have to been applied in the respective area of the imported model. The pressure obtained for different materials used here are tabulated in a table 3.

While calculating the pressure the self-weight of the each bumper are calculated. From that, the forces are calculated by multiplying it with the acceleration due to gravity. Since the assumption used here is that dynamic load acted is only due to self-weight of the bumper, it is acted at the inner surface of the bumper which is clearly identified from the fig 5 .

Force calculated is converted into pressure by adopting the value of surface area of the face where pressure is applied. The boundary condition used in this case is that two clamps are fixed, in other words we can say that all the motions are arrested which can be identified from figure 5. The value of surface area is found by using CATIA software and the mass of the different bumpers by using ANSYS Workbench itself.

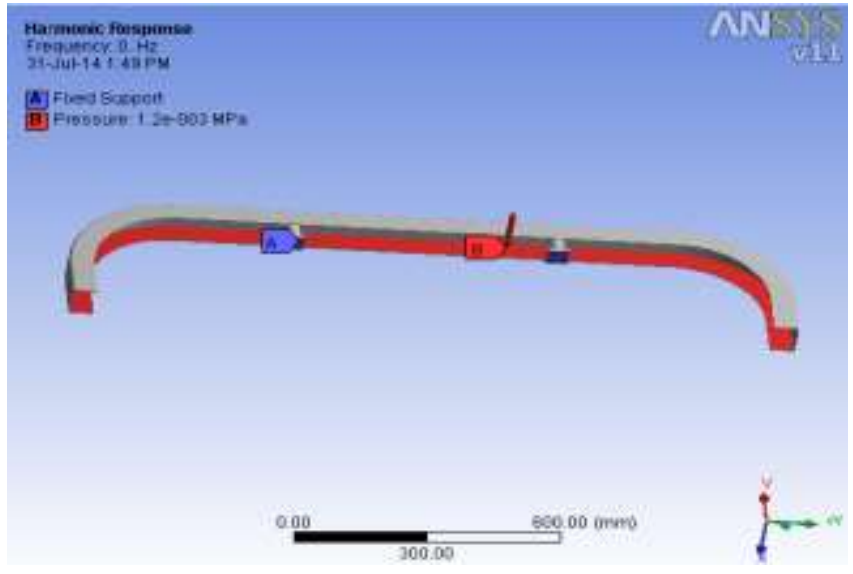

Fig. 5: Load and boundary condition applied in the dynamic loading case.

After doing the finite element analysis like static, impact, modal and the analysis under dynamic loading by varying materials and without changing geometry, required results are obtained. And these results are discussed in the next section.

\section{RESUlTS AND DisCUSSION}

The results obtained during various analysis like status, impact and modal analysis are discussed later. Also analysis under dynamic loading is also mentioned in the discussion.

\section{A. Static Analysis results}

The results obtained for the static condition with this model is tabulated in table 4. The pictorial representation of the stress contour and the deformation obtained when by changing the material as chromium coated mild steel during3 static analysis is given in figures 6 .The maximum stress is obtained is $958.72 \mathrm{MPa}$. The deformation value recorded is $273.2 \mathrm{~mm}$ and the maximum principal strain obtained in this case is 0.2128 .

TABLE IV.

STATIC ANALYSIS RESULT COMPARISON FOR DIFFERENT MATERIALS PRESSURE ACTED DOWNWARDS DUE TO MATERIAL SELF-WEIGHT

\begin{tabular}{|c|c|c|c|}
\hline Material & $\begin{array}{c}\text { Max. Von } \\
\text { mises Stress } \\
\text { (MPa) }\end{array}$ & $\begin{array}{c}\text { Max } \\
\text { principal } \\
\text { strain }\end{array}$ & $\begin{array}{c}\text { Deformation } \\
\text { (mm) }\end{array}$ \\
\hline $\begin{array}{c}\text { Chromium } \\
\text { coated Mild } \\
\text { Steel }\end{array}$ & 958.7 & 0.2128 & 273.2 \\
\hline $\begin{array}{c}\text { Aluminum } \\
\text { B390 alloy }\end{array}$ & 843.2 & 0.3325 & 422.4 \\
\hline $\begin{array}{c}\text { Carbon } \\
\text { composite }\end{array}$ & 1641 & 0.01619 & 21.18 \\
\hline
\end{tabular}




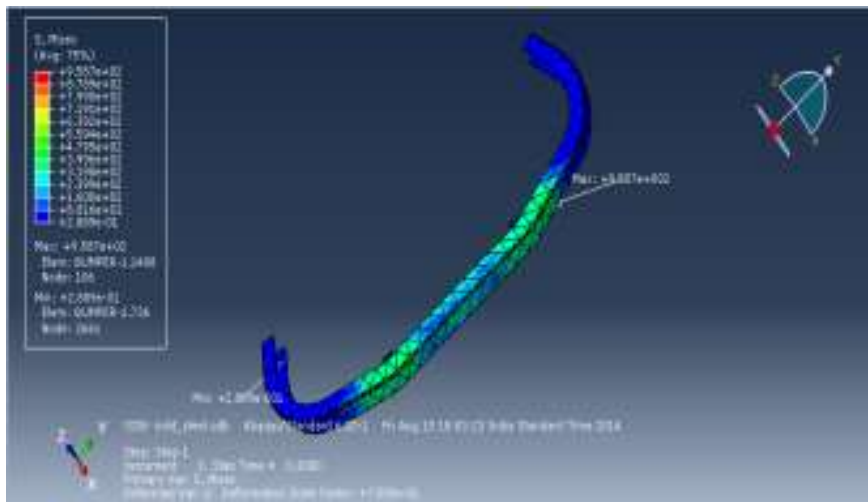

Fig. 6: Von mises' stress distribution for chromium coated mild steel

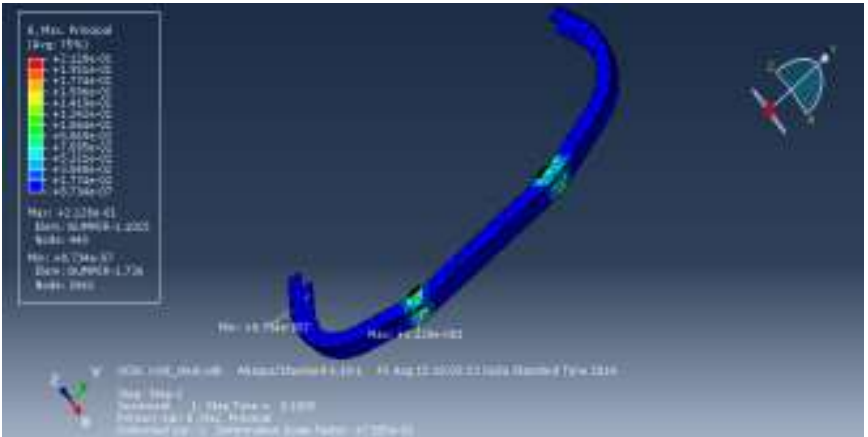

Fig. 7: Maximum principal strain obtained for chromium coated mild steel.

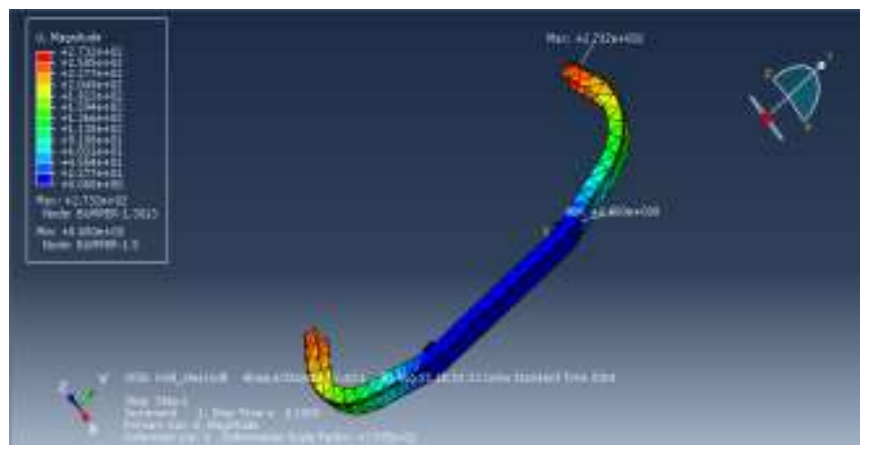

Fig. 8: Deformation obtained for chromium coated mild steel.

While analyzing the statically using ABAQUS for the material Aluminum B390 alloy, the maximum stress value obtained is $843.2 \mathrm{MPa}$. Von Mises stress is widely used by designers, to check whether their design will withstand given load condition. So while comparing Von mises stresses of the three materials in this analysis. Aluminum shows the second maximum Von mises' stress value. The deformation obtained in this case is $422.4 \mathrm{~mm}$, which is the maximum and maximum principal strain obtained is 0.3325 , which is also the maximum.

The pictorial representation of the stress contour for carbon composite is given in figure 9. The maximum stress is obtained is $1641.0 \mathrm{MPa}$. As compared with the other materials this material shows the maximum, since it is the strongest among all these. While considering the deformation the value obtained is $21.18 \mathrm{~mm}$ which is minimum for all. The maximum principal strain obtained for this material is 0.01619 and is the minimum of all.

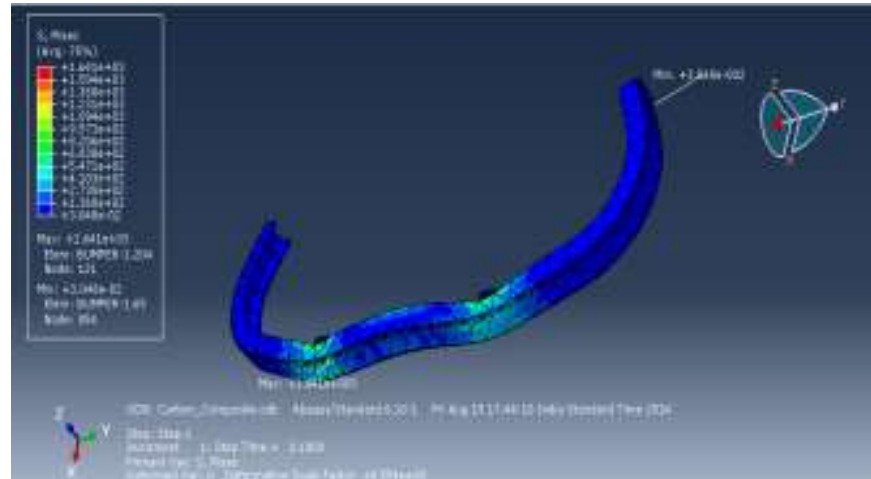

Fig. 9: Von mises' stress distribution for carbon composite

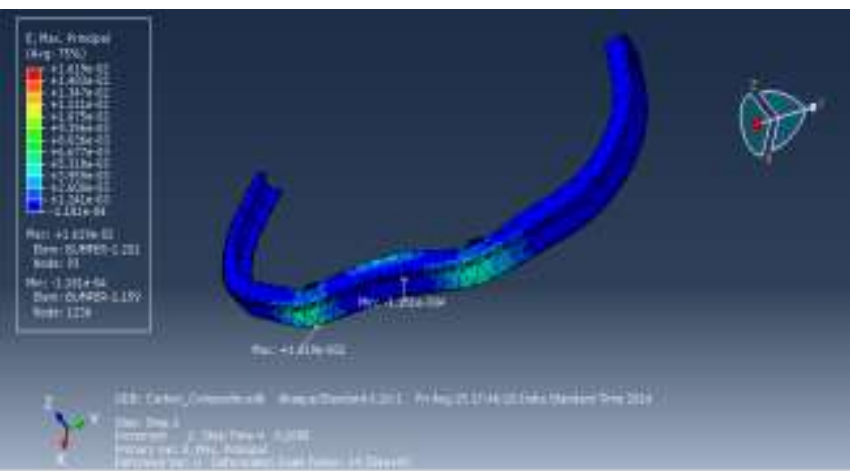

Fig. 10: Maximum principal strain obtained for carbon composite.

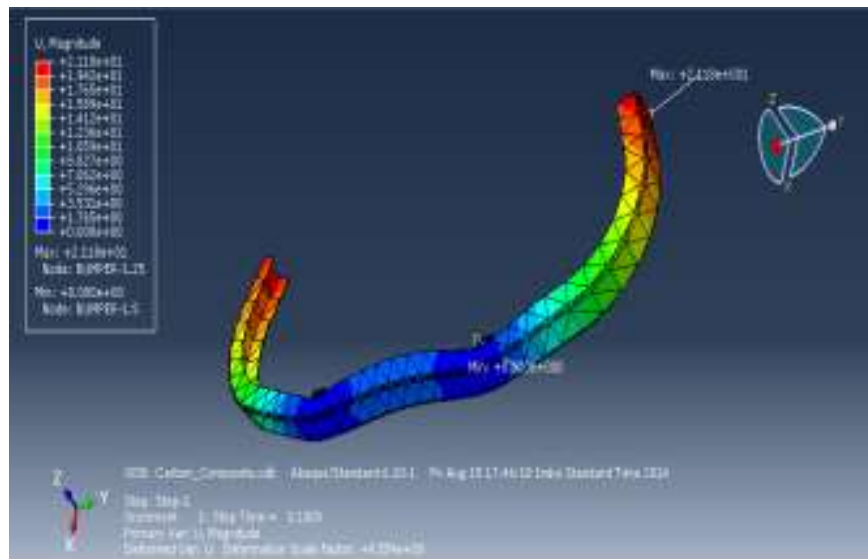

Fig. 11: Maximum principal strain obtained for carbon composite

\section{B. Impact Analysis results}

The results of this analysis are based on the design criteria called Von mises stress criteria, which arises from distortion energy failure theory. According to distortion energy theory failure occurs when the distortion energy in actual case is more than the distortion energy in a simple tension case at the time of failure.

The analysis of the chromium coated mild steel is done first. Among the four materials, this material shows the second maximum value for the von mises stress. Even though this material is having the maximum density, it shows only second maximum von mises stress value as $9.71 \mathrm{E}+02 \mathrm{MPa}$ which occurred in the front face of the bumper. One of the three material is a composite, which should always possess high strength, if it is lighter. 
TABLE V.

VARIOUS STRESSES AND DEFORMATION OBTAINED DURING IMPACT ANALYSIS.

\begin{tabular}{|c|c|c|c|}
\hline Material & $\begin{array}{c}\text { Max. Von } \\
\text { mises' stress } \\
\text { (MPa) }\end{array}$ & $\begin{array}{c}\text { Max. } \\
\text { deformation } \\
\text { (mm) }\end{array}$ & $\begin{array}{c}\text { Maximum } \\
\text { Logarithmic } \\
\text { strain }\end{array}$ \\
\hline $\begin{array}{c}\text { Mild steel } \\
\text { chromium } \\
\text { coated) }\end{array}$ & $9.71 \mathrm{E}+02$ & $1.51 \mathrm{E}+02$ & $6.66 \mathrm{E}+00$ \\
\hline $\begin{array}{c}\text { Aluminum } \\
\text { B390 alloy }\end{array}$ & $8.46 \mathrm{E}+02$ & $1.96 \mathrm{E}+02$ & $2.18 \mathrm{E}+00$ \\
\hline $\begin{array}{c}\text { Carbon } \\
\text { fiber } \\
\text { composite }\end{array}$ & $2.44 \mathrm{E}+04$ & $1.27 \mathrm{E}+02$ & $9.61 \mathrm{E}-01$ \\
\hline
\end{tabular}

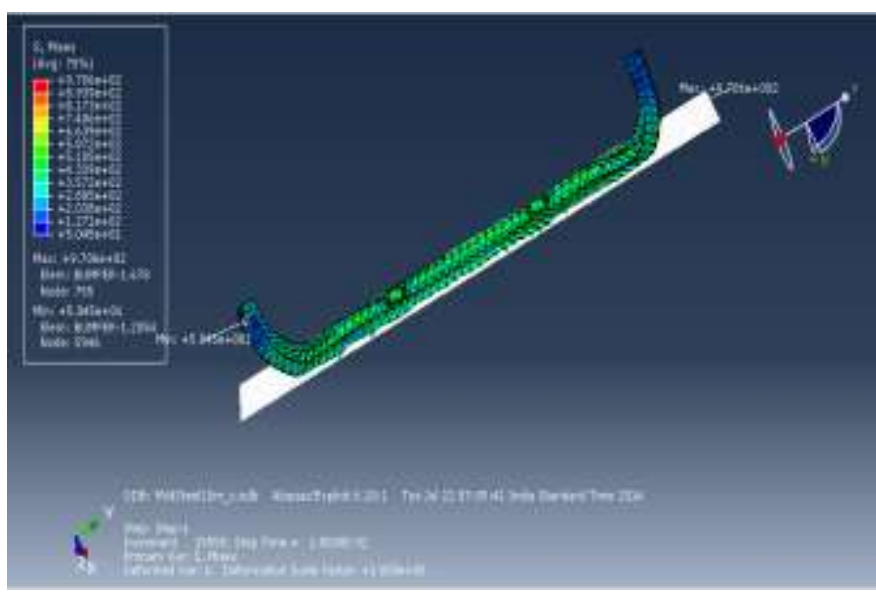

Fig. 12. Von mises stress obtained for chromium coated mild steel.

In the case of the deformation, this material having the minimum value among the ductile materials used here and second minimum among all, its value is $1.51 \mathrm{E}+02 \mathrm{~mm}$, it can be seen at the circular portion of the bumper. The strain component also shows the second minimum value as in the case of deformation, it shows the minimum for all ductile material. Since the chromium coated mild steel is the hardest of all the ductile materials used here, thus it shows these type of behavior. The strain component value for this case obtained value is 6.66, which is the second minimum of all and is recorded at the front face itself. And they are represented from figures 12 to 14 .
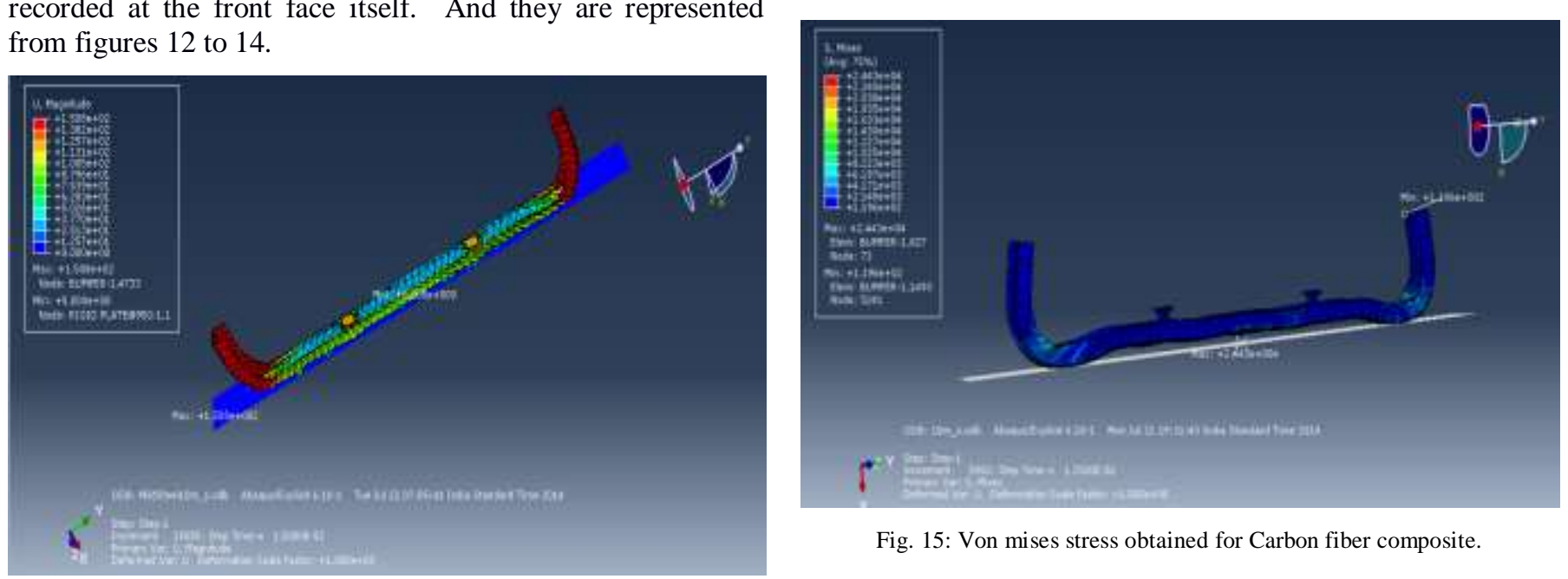

Fig. 15: Von mises stress obtained for Carbon fiber composite.

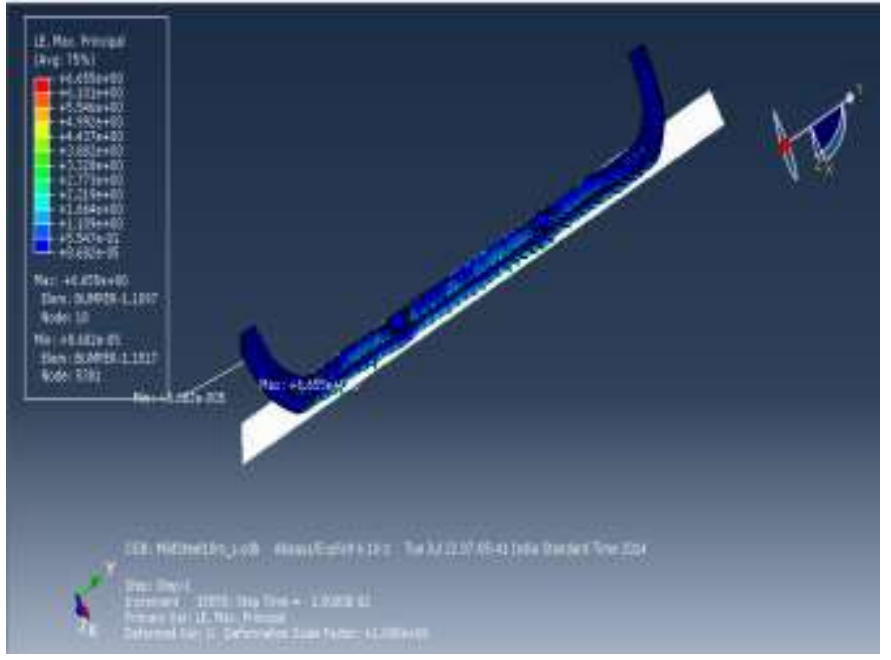

Fig. 14: Logarithmic strain obtained for chromium coated mild steel.

The next material used for analysis is the Aluminum B390 alloy. This is the second lightest among the all ductile materials used here. The value of maximum von mises stress recorded for this material is $8.46 \mathrm{E}+02 \mathrm{MPa}$, which is the second minimum of all the materials. It is recorded at the front face itself. Even though this alloy is stronger than aluminum but not strong enough stronger than the composite and the chromium coated mild steel. Maximum deformation recorded here is the second maximum, among all these materials ,its value is $1.96 \mathrm{E}+02 \mathrm{~mm}$, is recorded at the circular edge of the model, reason is simple as mentioned earlier, it is the second lightest among the ductile materials used. The strain component also shows he second maximum of all and the value is 2.18 and is obtained at the front face.

Finally the analysis was done on the composite. This material shows the highest value of maximum von mises stress among all the others. The value is $2.44 \mathrm{E}+04 \mathrm{MPa}$, and is obtained at the front face of the bumper. It shows the lowest deformation, because it possess high strength and its value is $1.27 \mathrm{E}+02 \mathrm{~mm}$, is recorded at the circular portion of the model.

Fig. 13. Deformation obtained for chromium coated mild steel. 


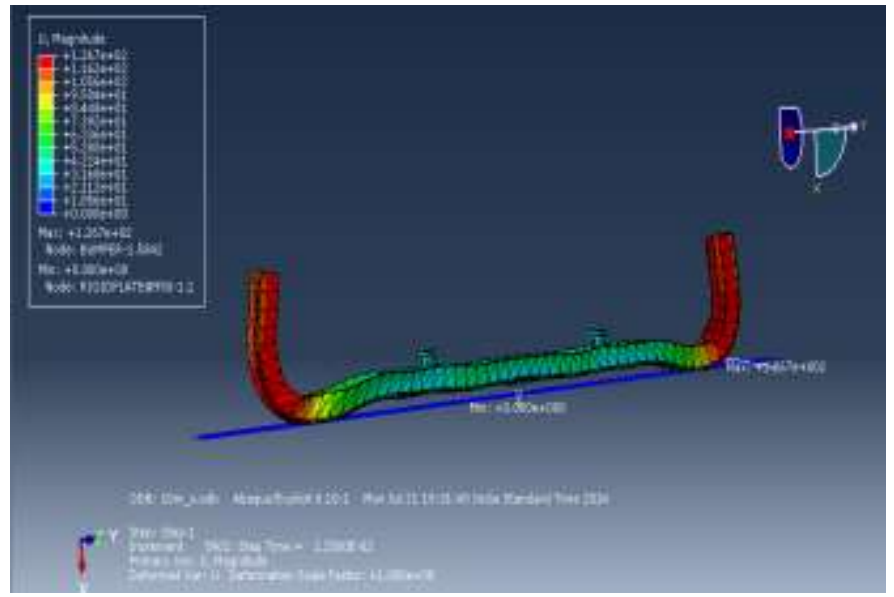

Fig. 16: Deformation obtained for Carbon fiber composite.

As in the case of deformation it shows the strain component also as the lowest of all, its value is $0.961 \mathrm{~mm}$ and is recorded at the front face of the model where it is hitted on the plate. These behavior of this material is due to the properties like high stiffness, high tensile strength, low weight etc. The result obtained for this material can be verified by from figures 15 to 17 .

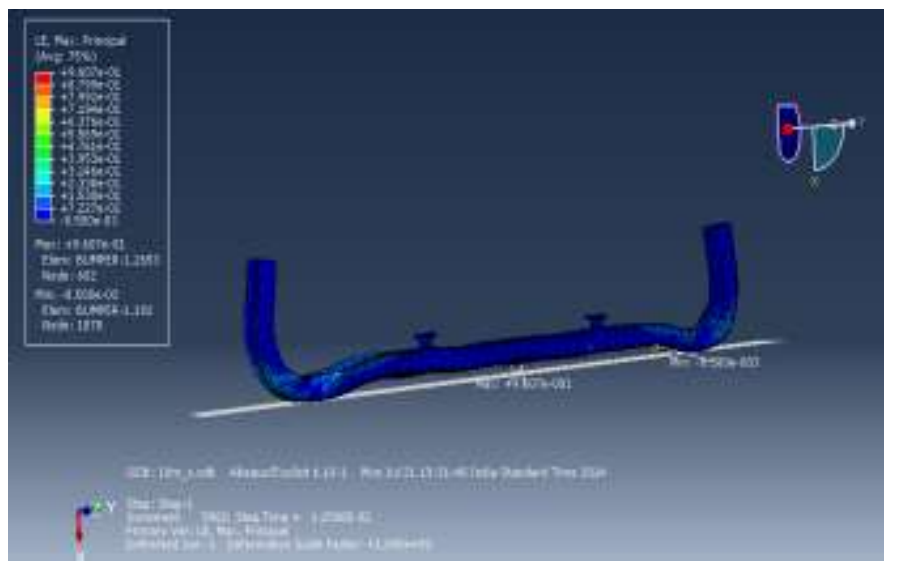

Fig. 17: Logarithmic strain obtained for Carbon fiber composite.

\section{Modal Analysis Results}

The results obtained for the modal analysis of three different materials are discussed under this section. While doing the analysis, the natural frequencies are found out. Natural frequency is the frequency at which a system tends to oscillate in the absence of any driving or damping force. Free vibrations of any elastic body is called natural vibration and happens at a frequency called natural frequency. Natural vibrations are different from forced vibration which happen at frequency of applied force (forced frequency). If forced frequency is equal to the natural frequency, the amplitude of vibration increases manifold which is known as resonance. As we studied earlier, the value of natural frequency will depend on the stiffness and the mass of the material. Mass will varied for each material which is also depend upon the value of density. Like that the stiffness will depend on the force and the deflection of the geometry. Since all the geometries taken in these analysis are identical, the chances for the variation of the frequencies are only due to the change in the density of the materials.
TABLE VI.

NATURAL FREQUENCIES OBTAINED FOR THE MATERIALS USED

\begin{tabular}{|c|c|c|c|}
\hline \multirow[b]{2}{*}{$\begin{array}{l}\text { Mode } \\
\text { No. }\end{array}$} & \multicolumn{3}{|c|}{ Frequency $(\mathrm{Hz})$} \\
\hline & $\begin{array}{c}\text { Chromium } \\
\text { coated mild } \\
\text { steel }\end{array}$ & $\begin{array}{c}\text { Carbon } \\
\text { fibre } \\
\text { composite }\end{array}$ & $\begin{array}{l}\text { Aluminum } \\
\text { B390 alloy }\end{array}$ \\
\hline 1 & 0 & 0 & 0 \\
\hline 2 & 0 & 0 & 0 \\
\hline 3 & 0 & 0 & 0 \\
\hline 4 & $2.40 \mathrm{E}-02$ & $2.78 \mathrm{E}-02$ & $1.14 \mathrm{E}-02$ \\
\hline 5 & $2.77 \mathrm{E}-02$ & $3.77 \mathrm{E}-02$ & 4.44E-02 \\
\hline 6 & 4.54E-02 & $5.10 \mathrm{E}-02$ & 4.96E-02 \\
\hline 7 & 85.631 & 121.11 & 90.464 \\
\hline 8 & 102.08 & 143.05 & 109.19 \\
\hline 9 & 194.57 & 274.24 & 206.18 \\
\hline 10 & 208.63 & 294.78 & 220.49 \\
\hline
\end{tabular}

Here the first modal analysis was carried out for the chromium coated steel. For this material, the frequency recorded for the first mode shape is $0 \mathrm{~Hz}$ and the tenth mode shape is having $208.63 \mathrm{~Hz}$ frequency. Normally a body have 6 degrees of freedom, three translational and three rotational along $\mathrm{x}, \mathrm{y}$ and $\mathrm{z}$ axis. Here the first mode shape is the translational motion in $x$ axis. Second is the rotational mode shape in the $x$ axis, then the third mode shape is the translational in the y direction which is followed rotation by $y$ direction motion of the model as the fourth mode shape. After this the same type of motions are repeating in the $\mathrm{z}$ direction as in the form of fifth and sixth mode shapes. All the corresponding frequencies and its deformation of the different modes upto ten are tabulated in table 6. Our interest is to focus on the mode shape 3 and mode shape 9 because they are occurring in the y direction, which is coming under our application. Nineth mode shapes was given here as fig 18 . In the third mode shape frequency is $0 \mathrm{~Hz}$ while in the ninth mode shape the frequency obtained is $194.57 \mathrm{~Hz}$.

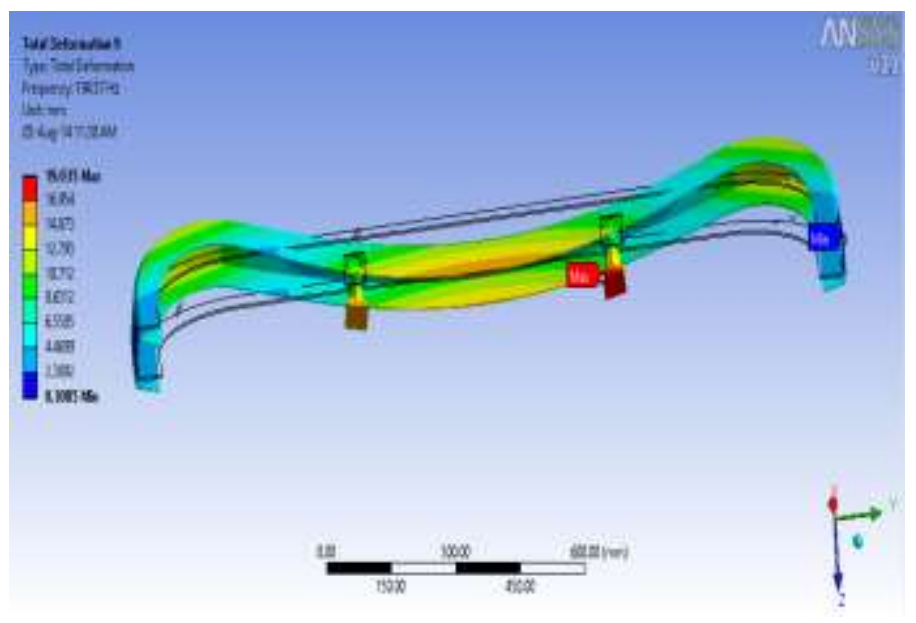

Fig. 18: Nineth mode shape of Mild Steel.

The next analysis were carried out for Carbon fiber composite. For this material, the frequency recorded for the first mode shape is $0 \mathrm{~Hz}$ and the tenth mode shape is having $294.78 \mathrm{~Hz}$ frequency. Since the geometry is not changing, it also have 6 degrees of freedom, three translational and three 


\section{International Journal of Engineering Trends and Technology (IJETT) - Volume 15 Number 7 - Sep 2014}

rotational along $\mathrm{x}, \mathrm{y}$ and $\mathrm{z}$ axis. Here the first mode shape is the translational motion in $\mathrm{x}$ axis. Second is the rotational mode shape in the $\mathrm{x}$ axis, then the third mode shape is the translational in the $y$ direction which is followed rotation by $\mathrm{y}$ direction motion of the model as the fourth mode shape. After this the same type of motions are repeating in the $\mathrm{z}$ direction as in the form of fifth and sixth mode shapes.

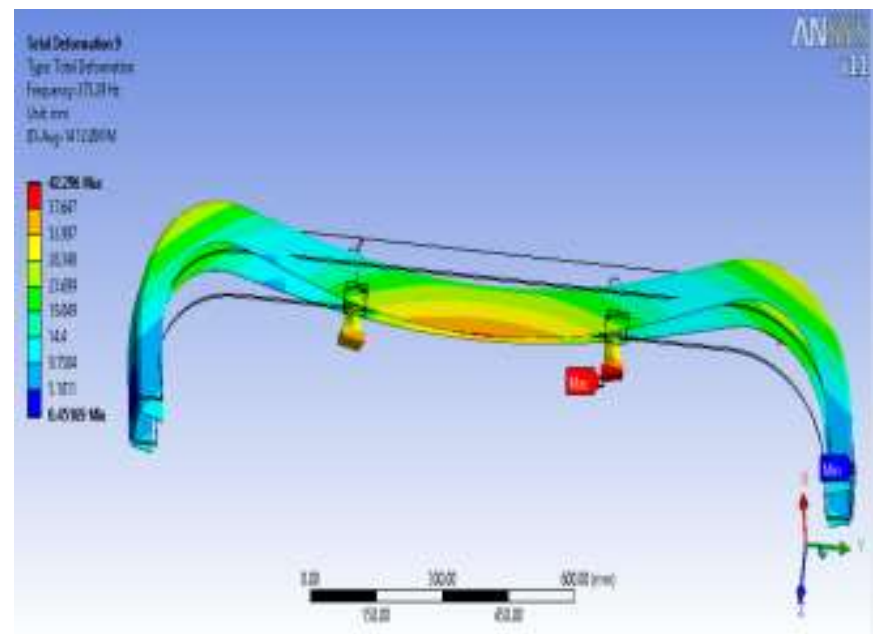

Fig. 19: Nineth mode shape of Carbon fiber composite

All the corresponding frequencies and its deformation of the different modes upto ten are tabulated in table 6. Our interest is to focus on the mode shape 3 and mode shape 9 because they are occurring in the y direction, which is coming under our application. Nineth mode shapes was given here as fig 19. In the third mode shape frequency is $0 \mathrm{~Hz}$ while in the ninth mode shape the frequency obtained is $274.24 \mathrm{~Hz}$.

The next analysis were carried out for Aluminum B390 alloy. For this alloy, the frequency recorded for the first mode shape is 0 and the tenth mode shape is having $220.49 \mathrm{~Hz}$ frequency. It also have 6 degrees of freedom, three translational and three rotational along $\mathrm{x}, \mathrm{y}$ and $\mathrm{z}$ axis. Here the first mode shape is the translational motion in $x$ axis. Second is the rotational mode shape in the $\mathrm{x}$ axis, then the third mode shape is the translational in the $\mathrm{y}$ direction which is followed rotation by $y$ direction motion of the model as the fourth mode shape. After this the same type of motions are repeating in the $\mathrm{z}$ direction as in the form of fifth and sixth mode shapes. In these analysis the frequency value is changing because of the change in material properties.

All the corresponding frequencies and its deformation of the different modes from one to ten are tabulated in table 6 . Our interest is to focus on the third mode shape and ninth mode shape, because they are occurring in the y direction, which is coming under our application. In the third mode shape frequency is $0 \mathrm{~Hz}$ and its deformation is $32.078 \mathrm{~mm}$ while in the ninth mode shape the frequency obtained is 187.77 $\mathrm{Hz}$ and its corresponding deformation is $38.961 \mathrm{~mm}$.

If we are comparing the results obtained for the modal analysis, we can easily identified that composite shows the highest natural frequency among the three. Since the frequency depends upon the mass for the same geometry with different materials. And the mild steel shows the minimum value for the frequency which is due to the high density of this material.

\section{Results on Dynamic Analysis}

While doing this analysis a frequency should give as input. The selection of the frequency is depended upon the mode shape. The frequency at the first mode having non zero value is given as an input. For taking the deformation, stress and strain components a frequency value had to give as an input. As did in the early analyses, here also the three materials are changing simultaneously. The results under dynamic condition for the various materials are given in table. 7 .

TABLE VII

RESULTS AFTER UNDER DYNAMIC LOADING CONDITION

\begin{tabular}{|c|c|c|c|}
\hline Material & $\begin{array}{c}\text { Frequency } \\
\text { (Hz) }\end{array}$ & $\begin{array}{c}\text { Max. Von } \\
\text { mises stress } \\
\text { (MPa) }\end{array}$ & $\begin{array}{c}\text { Max. } \\
\text { displacement } \\
\text { (mm) }\end{array}$ \\
\hline $\begin{array}{c}\text { Mild steel } \\
\text { chromium } \\
\text { coated) }\end{array}$ & 85.6 & 3.1371 & 0.2065 \\
\hline $\begin{array}{c}\text { Carbon } \\
\text { Composite }\end{array}$ & 121.1 & 2.9417 & 0.4669 \\
\hline $\begin{array}{c}\text { Aluminum } \\
\text { B390 alloy }\end{array}$ & 90.4 & 3.119 & 0.52695 \\
\hline
\end{tabular}

This analysis were first carried out with the chromium coated mild steel. While doing this analysis, damping ratio is input as 0.01 . And after solving the problem, we have to find out the stress, strain and the deformation components at a particular frequency. For this material the total deformation were obtained as $0.2065 \mathrm{~mm}$ which is the minimum of all, its corresponding von mises stress and obtained are 3.1371 MPa. The value obtained is the highest of all in the case of deformation and strain, but the stress just behind composite. Since this material is the strongest of all, and thus it shows very low deformation. The results are shown in the figures 20 and 21 representing the frequency response, stress and the deformation components.

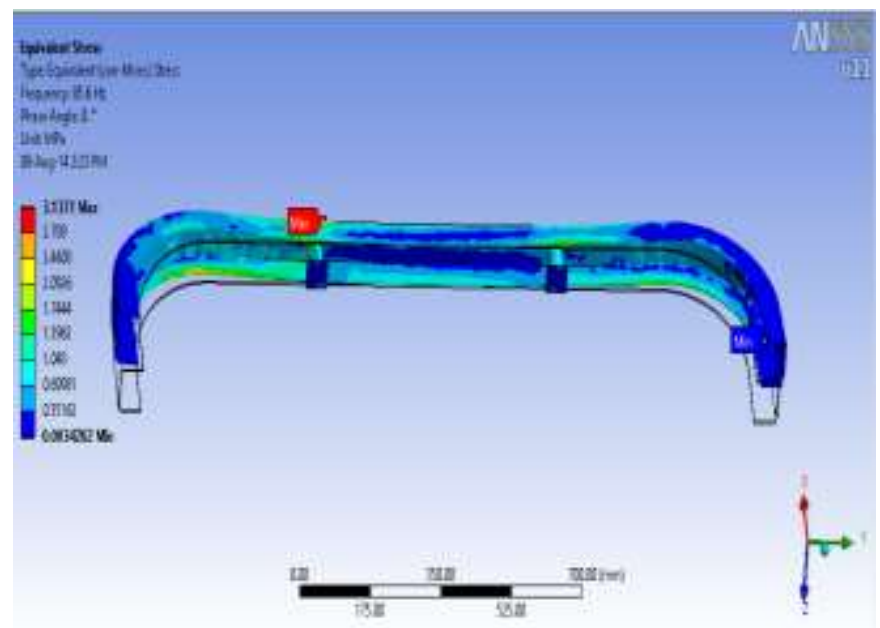

Fig. 20: Maximum Von mises stress obtained for Mild Steel during dynamic loading 


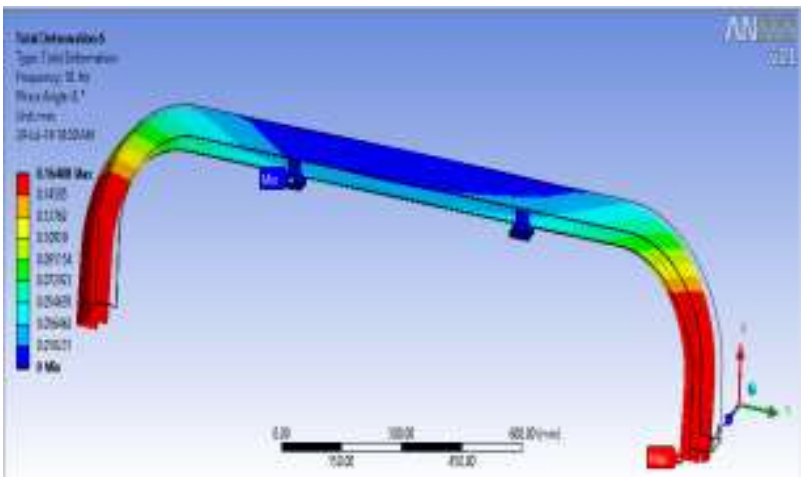

Fig. 21: Maximum deformation obtained for Mild Steel during dynamic loading

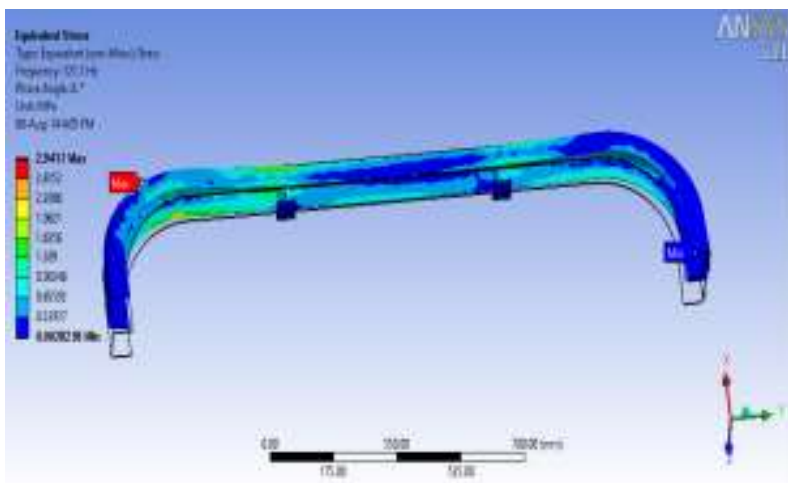

Fig. 22: Maximum Von mises stress obtained for Carbon composite during dynamic loading

The next analysis were carried out with the carbon composite as the material. While doing this analysis, the damping ratio is input as 0.01 as same in the earlier case. After solving the problem, the stress, strain and the deformation components at a particular frequency, here it is 121.1 Hz. For this material the total deformation were obtained as $0.4669 \mathrm{~mm}$ which is the second minimum, just behind chromium coated mild steel, its corresponding von mises stress and strain obtained are $2.9417 \mathrm{MPa}$.

Even though this material is the lightest of all, due to high strength to weight, it shows very high less value. The stress induced in a composite material is the least. So it is the best for dynamic loading. The results are shown in the figures 22 and 23 , representing the stress, frequency response and the deformation components.

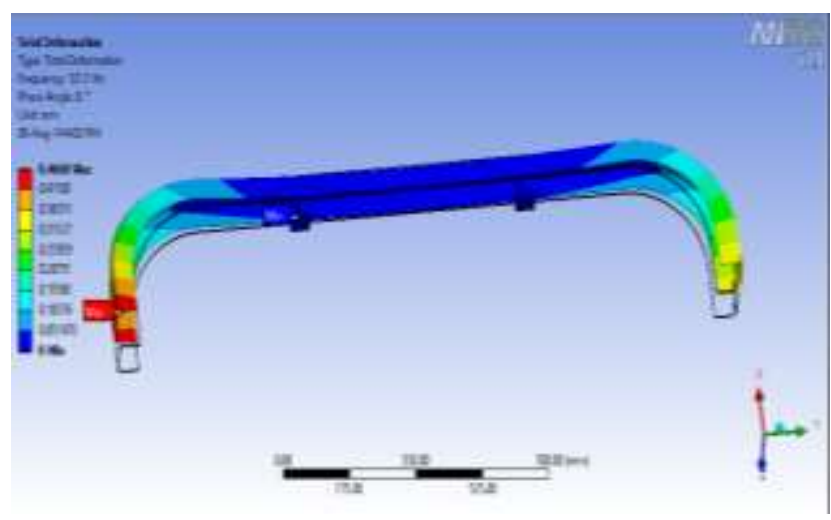

Fig. 23. Maximum deformation obtained for Carbon composite during dynamic loading.
The next analysis were carried out with the Aluminum B390 alloy bumper. While doing this analysis, the damping ratio is input as 0.01 as same in the earlier case. And after solving the problem, the stress, frequency response and the deformation components at a particular frequency of 121.11 $\mathrm{Hz}$. For this material the total deformation were obtained as $0.52695 \mathrm{~mm}$ which is the maximum of all, its corresponding von mises stress obtained are $3.119 \mathrm{MPa}$. The value obtained is the minimum of all in the case stress.

\section{CONCLUSION}

An Ambassador Car bumper is successfully modelled in modelling software CATIA V5R18. And this model is analysed statically and then finite element analysis on impact using ABAQUS V6.10 successfully. Then analysis on dynamic stability with the mode shapes is done using ANSYS Workbench 11.0.Among the three materials (two alloys and a composite) used for the static analysis, carbon fibre composite possess highest von mises stress value and the lowest deformation, which suits the best among the three. During the impact analysis maximum von misses stress is obtained for composite than on other materials like Chromium coated mild steel, Aluminium B390 alloy is observed. The composite also shows the lowest deformation and the lowest strain value on comparison with the materials like Aluminum B390 alloy and chromium coated mild steel. Aluminium B390 alloy shows the minimum von mises stress as well as the maximum value for strain and deformation, but not suitable for this purpose.

In the modal analysis also due to low density, the composite shows the maximum frequency as well as the deformation. The reason may be due to the limitation of providing all the composite properties in that software. During analysis under dynamic loading, the carbon composite exhibit the low von mises stress value but deformation slightly higher the minimum of all, due to the same reason as mentioned earlier. The stress induced in a composite during dynamic loading is less. So it is best under dynamic loading. By using the results under impact analysis and the modal analysis and analysis under dynamic loading, can be concluded that the composite is the best material that suits vehicle bumper.

One of the major limitation of the current work is that, various aerodynamic shapes are not used. Due to high cost the model, composites could not be fabricated and experimental analysis could not be attempted. All the composite properties cannot be input into the ANSYS Workbench 11.0. This requires changing of the number of elements for the bumper with same material.

In the future work a cost analysis can be done. More materials, composites and alloys will used as materials in future. Further analysis on environmental impact can be done using the Life Cycle Assessment software and carbon calculator tools. An experimental analysis can be proposed after fabricating the model with these materials for the validation of the result.

From various analysis, it is concluded that carbon composite meets most of the requirements like high strength to weight ratio, crashworthiness and high stiffness to weight ratio. The chromium coated mild steel material used currently 
for bumpers in the Ambassador having high weight. Carbon composite can reduced the weight upto 5 times for the same bumper. This composite also provides high von misses stress values and less deformation than the other materials used here.

\section{ACKNOWLEDGEMENT}

The authors would like to thank GOD ALMIGHTY for His unseen hand, which guided and strengthened us, even at times when we felt, we were not capable of doing it ourselves.

\section{REFERENCES}

[1] Karol Bielefeldt, Władysław Papacz and Janusz Walkowiak "Environmentally friendly car plastics in automotive engineering", University of Zielona Góra, Institute of Mechanical Engineering and Machine Operation, 2007.

[2] A. Hambali1, S. M. Sapuan, N. Ismail and Y. Nukman, "Application of analytical hierarchy process in the design concept selection of automotive composite bumper beam during the conceptual design stage", Scientific Research and Essay, April 2009, Vol. 4 (4) pp. 198 211.
[3] Hwa Won Lee and Sung Kuk Jang, "Bumper design using computer simulation", 1993.

[4] Javad Marzbanrad, Masoud Alijanpour and Mahdi Saeid Kiasat, "Design and analysis of an automotive bumper beam in low-speed frontal crashes", thin-Walled Structures, 2009, Vol. 47 902-911.

[5] S.M. Sohn, B.J. Kim, K.S. Park and Y.H. Moon, "Evaluation of the crash energy absorption of hydroformed bumper stays", Journal of Materials Processing Technology ,2007, 188 :283-286. [6] "Details of
http://www.nhtsa.gov/cars/problems/studies/bumper/

bumper"-

[7] Research Council for Automobile Repairs, "RCAR Bumper Test", Issue 2.0, September 2010 .

[8] "Bumper analysis"'http://www.umpir.ump.edu.my/1097/1/Jamail_Jamal.pdf

[9] "Details of usage of Aluminum in automobiles" http://www.drivealuminum.org/aluminum-advantages/sustainability

[10] Simonetta Boria, 2011, Lightweight design and crash analysis of composite frontal impact energy absorbing structures. Composite Structures 94 (2012) 423-430.

[11] Finite Element Analysis-www.wikipedia.org/ finite+element+analysis/

[12] Alen John and Nidhi M.B, "Modelling and finite element analysis of automotive bumper under static loading", National conference on advances in mechanical engineering-2014, pp.09-13. 